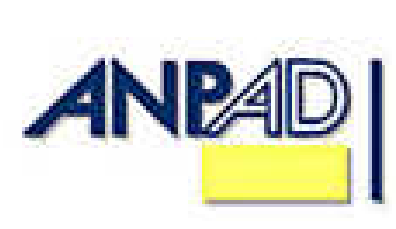

Available online at

http://www.anpad.org.br/bar

BAR, Curitiba, v. 6, n. 4, art. 2,

pp. 299-315, Oct./Dec. 2009

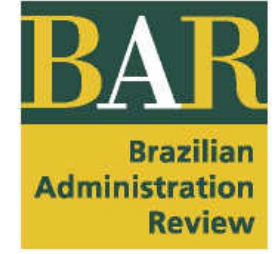

\title{
Organizational Institutionalism in the Academic Field in Brazil: Social Dynamics and Networks
}

\author{
Edson Ronaldo Guarido Filho * \\ E-mail address: edson.guarido@gmail.com \\ Programa de Mestrado e Doutorado em Administração/Universidade Positivo - PMDA/UP \\ Curitiba, PR, Brazil.
}

Clóvis L. Machado-da-Silva

E-mail address: clms@terra.com.br

Universidade Federal do Paraná - CEPPAD/UFPR and Universidade Positivo - PMDA/UP

Curitiba, PR, Brazil.

\section{Sandro Aparecido Gonçalves}

E-mail address: sag2@uol.com.br

Programa de Mestrado e Doutorado em Administração/Universidade Positivo - PMDA/UP

Curitiba, PR, Brazil.

\begin{abstract}
This article is based on the assumption that the construction of scientific knowledge is a social process characterized by the recursive dynamic between the social and intellectual dimensions. In light of this statement, we investigated how the construction of the institutional perspective is delineated in the context of organizational studies in Brazil from 1993 to 2007. The study is based on documentary research of articles published in scientific journals and at academic events. For this purpose, we analyzed social networks and used bibliometric indicators in order to map the cooperation relationships between researchers and intellectual framework, based on the cited authors. The results show the influence of social relationships in the process of constructing scientific knowledge. The findings reveal that the expansion of the field is based on the growing elaboration of a social organization with close links to the activities of continuant and transient researchers. These circumstances denote the stratification both of production and the relationships between authors, since continuant and transient researchers are responsible for the intermediation of relations and the consolidation of production in the academic field that is being analyzed. The findings also reveal a secondary dynamic of the activities of researchers located on the margin of the network and the presence of Brazilian researchers among the most cited authors, an indication of a legitimized local intellectual base.
\end{abstract}

Key words: institutional theory; organizational studies; scientific knowledge; social network; bibliometric analysis.

Received 30 March 2009; received in revised form 17 June 2009.

Copyright (C) 2009 Brazilian Administration Review. All rights reserved, including rights for translation. Parts of this work may be quoted without prior knowledge on the condition that the source is identified.

\footnotetext{
* Corresponding author: Edson Ronaldo Guarido Filho

Programa de Mestrado e Doutorado em Administração (PMDA), Universidade Positivo (UP), Rua Prof. Pedro Viriato Parigot de Souza, 5300, Prédio da Biblioteca, $5^{\circ}$ andar, Curitiba/PR, 81280-330, Brazil.
} 


\section{INTRODUCTION}

The field of organizational studies has broadly developed over the past fifty years. In the course of these five decades, different theoretical perspectives have been developed and put to the test, making it a highly creative period. Different rational models have been contrasted and also combined with others that place emphasis on political or cultural dimensions, showing the growing concern over broader levels of analysis and different facets of the environment (Scott, 2001).

In this context, one perspective in particular has been increasingly highlighted: organizational institutionalism, notably its sociological realm (Dacin, Goodstein, \& Scott, 2002; Farashahi, Hafsi, \& Molz, 2005; Machado-da-Silva \& Fonseca, 1993; Mizruchi \& Fein, 1999; Scott, 2001). According to Greenwood, Oliver, Sahlin and Suddaby (2008), the institutional theory is probably the dominant approach in organizational studies. In their turn, Haveman and David (2008) state that it constitutes the predominant perspective in the submissions to the Organization and Management Theory Division at the recent annual meetings of the Academy of Management. In Brazil, data of this nature are not yet available, but the adherence of researchers and the growing number of studies from this perspective is notable, according to Machado-da-Silva, Fonseca and Crubellate (2005), Rossoni (2006), Caldas and Fachin (2007) and Guarido Filho (2008).

From the point of view of the sociology of knowledge, we consider it important to understand the social processes involved in the construction of scientific knowledge regarding to the intellectual program of the field. In this sense, it would be plausible to raise the question of how the institutional perspective program evolved and how much it has been gaining in prominence in the scientific community. Before that, however, it is necessary to map the development of organizational institutionalism, and it was with this purpose in mind that we sought in this article to trace the trajectory of the institutional perspective in the field of organizational studies in Brazil from empirical data concerning the scientific publications ranging from 1993 to 2007. We also use the expression organizational studies to include works classified as strategy in organizations on Brazilian territory, as it does not make sense to treat them separately when the institutional analysis perspective is used.

Therefore, the present study aims to evaluate the institutionalization of the institutional theory in organizational studies in Brazil from descriptive indicators of a longitudinal base that portray the origin and the expansion that has taken place in recent years.

To this end, the article has been organized into four sections in addition to this introduction. In order to position the reader on the aspects upon which this article is based, the first section deals with our preliminary considerations concerning organizational institutionalism and the construction of scientific knowledge. This is followed by a description of the methodological procedures we have used in the empirical examination of articles published in national academic outlets over the period 1993-2007. The results are presented in the third section, where we discuss through network analysis and bibliometric indicators (i) the quantitative expansion of the number of researchers and papers based on organizational institutionalism, (ii) the network structure of cooperation among researchers and (iii) the theoretical framework of the papers in terms of the most cited authors. Conclusions and analytical implications are presented in the last section.

\section{THEORETICAL FrameWork}

\section{Concerning Organizational Institutionalism}

The institutional theory reflects transformations that occurred in the field of organizational studies, especially from the mid nineteen sixties, a period marked by works in favor of the open systems 
models (Scott, 1995). However, it differs from classic studies of organizations in the notion of the environment, no longer treated as an entity that lies outside the organization. This was due to (i) the greater focus on environmental attributes that are more specific to the interorganizational relationship instead of aspects that influence structures or behaviors of individual organizations, such as scarcity and complexity; (ii) the expansion of the level of analysis from a single organization and its closest partners to populations, communities and organizational fields; and especially (iii) the consideration of other environmental facets that involve symbolic aspects in the form of social and cultural elements that act in conjunction with the economic and material dimension (Scott, 1995).

Under the institutional perspective, attention is paid to the relationship of mutual influence between organizations and organizational fields on the one hand and broader normative and cultural structures on the other. This perspective pays attention to how institutionalized values in society permeate organizational structures and forms, considering it necessary to enrich analyses of instrumental aspects with reflections on cultural and symbolic elements in the organizational study. In this sense, legitimacy, often associated with adaptation and acceptability of social values, arises as a relevant category of analysis that is at the least equivalent to the importance ascribed to technical efficiency (DiMaggio \& Powell, 1983; Meyer \& Rowan, 1977; Scott, 2001). Thus, institutionalization is a process conditioned by the logic of conformity to socially accepted norms and the incorporation of a knowledge system constructed throughout social interaction, which constitute parameters both for action and for the conception of reality of social actors. Organizations, in this sense, articulate their behavior and structures in relation to the characteristics of the institutional context in search of legitimacy and social acceptance (DiMaggio \& Powell, 1983; Meyer \& Rowan, 1977; Scott \& Meyer; 1991).

In synthesis, we can state that, in organizational studies, this approach pays special attention to institutional aspects of the environment, in conjunction with their technical dimension. In this sense, it considers the implications concerning action and organizational behavior, but also investigates themes connected to the understanding of processes of production, maintenance and transformation of social norms and the ascension of institutional structures and organizational forms, encompassing their relationship with the influence of formal and informal norms, institutional change and cultural beliefs, among other matters (Powell, 1991; Scott \& Meyer, 1991).

\section{Concerning the Construction of Scientific Knowledge}

We agree, in accordance with Astley (1985), Davis (2006), DiMaggio (1995), Fuller (2002) and Weick (1995), that the construction of scientific knowledge is well understood as a social dynamic represented by a number of interactions of actors in a scientific field. In this process, to study an analytical perspective such as the institutional theory means recognizing that it embraces an ongoing social and theoretical (re)construction. As such, this means, on the one hand, enquiring about the ways in which ideas, concepts and their inherent assumptions become legitimate and last over time; on the other hand, and complementarily, it means understanding the peculiarities of this intellectual program. In other words, it is the investigation of the recursive process between the social and intellectual dimensions (Guarido Filho, 2008).

Thus, the action of researchers producing, interpreting and mobilizing themselves for their ideas are the object of research in light of the conditions of the academic organization and objectified knowledge, which are in turn a medium and outcome of scientific activity. We agree that the knowledge produced through scientific activity (normally taking the form of academic publications as articles) represent a certain world view which, when shared, influences interpretation and, therefore, the understanding of the phenomena under study. This does not preclude implications in the choice of research problems and strategies, analytical categories, validation criteria and other aspects associated with the dynamic of scientific activity. 


\section{Concerning the Aims of the Study}

Faced with the complexity involved in researching knowledge as a social process, we have opted to adopt a methodology that makes it possible to show, albeit descriptively, certain aspects that we consider relevant to the outcome of this study. In the case of the institutionalization of the institutional theory in organizational studies in Brazil, we understand that, as a state (unlike a process), a certain degree of permanence is presumed in the environment of scientific production, supported by a broad segment of researchers who cooperate in the sense of designing and adopting a theoretical framework that will enable some kind of differentiation in relation to other perspectives available in the field. Thus, we emphasize that the adopted procedures were guided for evidence that could indicate the settlement of the institutional analysis framework in the context of organizational studies. We are conscious that they do not represent all theoretical assumptions that we believe guide a broader line of research regarding the construction of scientific knowledge and that in this study they are only partially represented.

\section{Methodological Procedures}

The research design of this study is of a descriptive nature. On the one hand, it gives preference to the characterization of the academic community and the relationship structure between researchers and, on the other hand, it depicts the prevalence of cited authors in the references used by the scientific articles examined. Therefore, based on documentary research of articles published in Brazilian scientific outlets, we extracted data concerning the authorship and the cited references. The temporal perspective was longitudinal, with data collection ranging over a period of fifteen years, from $1993^{(1)}$ to 2007.

Articles were chosen based on their analytical focus guided by the theoretical framework of the institutional theory provided that they were published in annals of meetings of the Brazilian Academy of Management [ANPAD] (EnANPAD, EnEO and 3Es) or scientific journals with an editorial line that converges with the field of organizational studies. Both sources were classified as A National by the Brazilian Governmental Accreditation Agency of Graduate Programs [CAPES], in accordance with the ranking of June, $2007^{(2)}$. For greater confidence in the selection of articles, we triangulated data extracted directly from research sources, analyzing the content of the texts (restricted to their titles, abstracts, key words and introductory section); the results of an electronic search using key words on the website of the researched sources; and also, based on partial data available so far, the registers available from Lattes Platform concerning scientific production of the twenty most prominent researchers in terms of published articles.

All the articles selected were coded and tabulated for the construction of an organized database. From the articles, we extracted the identification of the authors, whose data enabled us to trace their cooperation relationships as represented by their co-authorship. Furthermore, we tabulated and codified all the references used in each paper in order to make viable citation analyses.

After these stages, 297 scientific articles had been selected, the result of the production of 256 researchers. As for the references, of a total of 10,445, we verified 4,625 different cited articles and 3,998 valid and distinct cited authors used in the articles in the field of the institutional perspective in organizational studies.

We used data referring to the authorship of the selected articles to evaluate the expansion of researchers and the social organization surrounding the institutional perspective. These data enabled us to describe the academic community through bibliometric indicators and the analysis of the social structure, based on collaboration networks among researchers in accordance with Liu, Bollen, Nelson 
and Van de Sopel (2005) and Moody (2004). The research method was quantitative through network analysis.

The rise of the institutional perspective in the field of organizational studies was evaluated quantitatively by the volume (absolute and relative) of articles, researchers and authorships for each year. The researchers, in their turn, were classified into continuants, transients, newcomers, terminators and one-timers, according to the regularity and distribution of their publications throughout the period. This classification was adapted from Braun, Glanzel and Schubert (2001) and Gordon (2007).

Finally, the collaboration structure among researchers was obtained by way of authorship data through which a matrix was constructed between authors and their respective articles (two-mode network) so that it could later be transformed into a square matrix of affiliation between authors, where each cell indicates the volume of occurrences of different pairs of co-authorship (one-mode network). Graphically, the representation of the affiliation matrix illustrates the collaboration structure for scientific performance in the field under study.

To analyze the cited authors, we evaluated their prominence by counting the number of citations each of them received in the articles published during the period under study. The ranking reflects the number of times that an author was cited in all the references extracted from the examined articles.

\section{RESULTS AND DISCUSSION}

The field of the institutional perspective in organizational studies showed signs of transformation during the period under study. Based on the data collected from the 297 articles selected for the purpose of this study, we found that the academic community in this specific field includes 256 researchers, the consequence of the sharp growth in the later years, as shown in Figure 1.

Figure 1: Production and the Academic Community Associated with Organizational Institutionalism

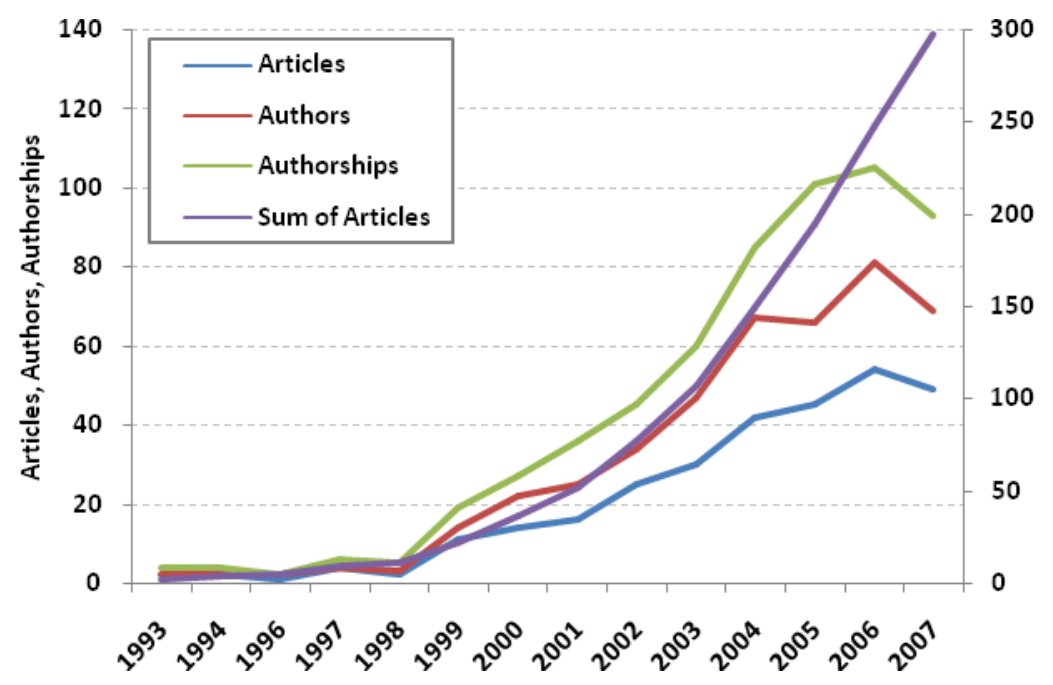

\begin{tabular}{|c|c|c|}
\hline Year & $\% \mathrm{C}$ & $\% \mathbf{P}$ \\
\hline 1993 & $0.8 \%$ & $0.7 \%$ \\
\hline 1994 & $0.8 \%$ & $0.7 \%$ \\
\hline 1996 & $0.8 \%$ & $0.3 \%$ \\
\hline 1997 & $1.6 \%$ & $1.3 \%$ \\
\hline 1998 & $1.2 \%$ & $0.7 \%$ \\
\hline 1999 & $5.5 \%$ & $3.7 \%$ \\
\hline 2000 & $8.6 \%$ & $4.7 \%$ \\
\hline 2001 & $9.8 \%$ & $5.4 \%$ \\
\hline 2002 & $13.3 \%$ & $8.4 \%$ \\
\hline 2003 & $18.4 \%$ & $10.1 \%$ \\
\hline 2004 & $26.2 \%$ & $14.1 \%$ \\
\hline 2005 & $25.8 \%$ & $15.2 \%$ \\
\hline 2006 & $31.6 \%$ & $18.2 \%$ \\
\hline 2007 & $27.0 \%$ & $16.5 \%$ \\
\hline TOTAL & 256 & 297 \\
\hline
\end{tabular}

Source: research results.

$\% \mathrm{C}=$ percentage in relation to the total number of researchers active that year; $\% \mathrm{P}=$ percentage in relation to the number of articles produced in that year. 
However, and more importantly for this study, the growth of the field is a sign of greater adherence of researchers to the analysis perspective under study, i.e., every year, new authors produce papers within the institutional approach, increasingly constituting a specialty, in that there is a certain continuous sharing of ideas. This can be seen through the growing number of researchers and articles appearing every year, reaching ever higher rates in 2006 and 2007. Respectively, during this period we found that $18.2 \%$ and $16.5 \%$ of the total number of articles were produced in the field, as well as the greater participation of researchers in the activity of scientific production, with around $31.6 \%$ and $27.0 \%$ of the community linked to the perspective involved in the publication of papers. In turn, the number of authorships strengthens these data but further indicates positive rates of collaboration between researchers for the purpose of scientific production.

This growing cooperation between authors is a strong indicator of the intellectual organization of the institutional perspective in vogue. Nevertheless, more categorical statements about the characteristics of this process cannot be made without complementary information being researched. For example, every year, only a part of the authors in the community produce new articles and publish them at the sources of our research. While some do this with a certain regularity, others publish only once and no longer produce papers rooted in organizational institutionalism. With this in mind, we categorized authors according to their volume and regularity of production in order to include additional elements to help understand scientific activity in the field.

\section{Continuants and Consolidation of Production}

Author categorization was based on the overall activity of the researchers during the period under study, considering the volume and regularity of their production (see Table 1). For each category we analyzed its representation in the field concerning the number of researchers involved and the volume of articles produced.

Table 1: Distribution of Researchers according to Production Categories and Continuity

\begin{tabular}{|c|c|c|c|c|c|}
\hline Category & Description & Authors & $\mathbf{A A}$ & $\mathbf{A P}$ & PP \\
\hline CONTINUANTS & $\begin{array}{l}\text { Published in } 5 \text { or more different years in the period } \\
\text { under study, with an average interval of up to two } \\
\text { years, with at least one in the last } 3 \text { years. }\end{array}$ & $\begin{array}{c}5.5 \% \\
(14)\end{array}$ & 186 & $\begin{array}{c}48.5 \% \\
(144)\end{array}$ & $\begin{array}{c}93.3 \% \\
(14)\end{array}$ \\
\hline
\end{tabular}

\begin{tabular}{|c|c|c|c|c|c|}
\hline TRANSIENTS & $\begin{array}{l}\text { More than one publication distributed over the } \\
\text { period analyzed in no more than } 4 \text { different years, } \\
\text { with at least one in the last } 3 \text { years. }\end{array}$ & $\begin{array}{c}16.4 \% \\
(42)\end{array}$ & 137 & $\begin{array}{l}36.4 \% \\
(108)\end{array}$ & $\begin{array}{c}60.0 \% \\
(9)\end{array}$ \\
\hline ONE-TIMERS & $\begin{array}{l}\text { Only one single publication in all the period under } \\
\text { study. }\end{array}$ & $\begin{array}{l}59.8 \% \\
(153)\end{array}$ & 153 & $\begin{array}{c}36.0 \% \\
(107)\end{array}$ & $\begin{array}{c}66.7 \% \\
(10)\end{array}$ \\
\hline NEWCOMERS & $\begin{array}{l}\text { More than one publication in one or more different } \\
\text { years in the last three years (exclusively). }\end{array}$ & $\begin{array}{c}10.2 \% \\
(26)\end{array}$ & 65 & $\begin{array}{c}17.2 \% \\
(51)\end{array}$ & $\begin{array}{c}20.0 \% \\
(3)\end{array}$ \\
\hline TERMINATORS & $\begin{array}{l}\text { More than one publication in one or more different } \\
\text { years, but none in the last three years. }\end{array}$ & $\begin{array}{l}8.2 \% \\
(21)\end{array}$ & 51 & $\begin{array}{c}12.8 \% \\
(38)\end{array}$ & $\begin{array}{c}40.0 \% \\
(6)\end{array}$ \\
\hline Total & & 256 & 592 & 297 & 15 \\
\hline
\end{tabular}

Note: $\mathrm{AA}=$ Authorships of Articles totals the presence of authors in the works produced. AP = Articles with Production; takes into account the number of publications in which authors from different categories made a contribution. Because many articles have more than one author, and from different categories, the sum of these indicators is higher than the total number of authors and articles in the field. PP = Periods with Production; considers the number of years, from 1993 to 2007 , in which there was an article produced by an author of the category.

Source: research results. 
The first aspect that deserves attention in this classification is the small number of continuant authors (only 14, according to the adopted criteria) in comparison with those classified as one-timers, who totaled 155 authors. Both categories, nevertheless, accounted for a high number of published articles (48.5\% and $36.0 \%$, respectively), but in very different proportions in terms of volume of researchers in the field: while the continuants represent only $5.5 \%$ of the total, the one-timers represented 59.8\%. According to the data in Table 1, the continuants have the highest average of involvement in papers, with total productivity equal to 13.3. The transients also stand out in this sense, since 42 researchers are associated with 137 articles produced in the field, with total productivity equal to 3.3 , higher than the newcomers (2.5), terminators (2.4) and one-timers (1.0). These data point to the fact that both categories, continuants and transients, should be recognized as exponents of the foundational bases and continuity of research in the field under study.

Concerning the large number of one-timers, although some of them may return to the field in the future with new publications, being reclassified as newcomers or transients, what calls attention is the fact that we are dealing with a single publication by each of these authors in the field under study. Indeed, some of these authors could be considered outsiders as their predominant interest lies in some other field of study and they have made only one contribution to the institutional perspective in organizational studies. However, it is more likely that the majority of papers published by one-timers are the product of master's degree dissertations with guidance from other researchers who are already established in the field, or else the result of a perceived window of opportunity by many researches due to the growth of the approach in the field of organizational studies. One-timers may also represent the attractiveness of the field as a suitable perspective for explaining organizational phenomena, thereby stimulating its expansion and visibility.

The data so far allow us to conclude that the institutional perspective in organizational studies follows a growth trajectory in terms of the number of articles published in the academic community. This expansion is sustained, to a certain extent, in the activity of continuant and transient authors who, together, are responsible for most of the papers published throughout the period under study, which points to the stratification of scientific production (see Merton, 1996) associated with a reduced number of authors, especially continuants.

\section{Continuants and Intermediation}

When comparing the cooperation patterns in relation to the categorization of authors, some points require attention. First, it is worth observing that the proportion of co-authored papers is $71.2 \%$ of production for all the period under study. Continuants and terminators are the groups with the highest proportion of authors who collaborate with others from different categories, followed by newcomers and transients. Furthermore, one-timers are the group with the lowest degree of involvement with other different categories. Moreover, one-timers have a higher rate (18.1\%) of isolated authors (with no cooperation) and also the highest number of authors whose links are restricted internally to their own category. All the other categories, inversely, behave in a way that favors relationships with others, and only a small number of authors have relationships exclusively within their own category. The positive E-I Index of 0.146 , calculated from the matrix of cooperation between researchers, with the categories of authors as an attribute, is proof of this aspect.

Among the continuants, the average number of co-authorship ties, i.e., the volume of cooperation relationships, is visibly higher than the others, with as many as $80 \%$ of authors maintaining connections with four or more authors. Another point that deserves to be mentioned is the high proportion of researchers whose collaborations are with researchers from other categories: continuants have connections with $18.1 \%$ of one-timers, $34.6 \%$ of newcomers, $45.2 \%$ of transients and $47.6 \%$ of terminators, a considerable participation in the intermediation of relationships of different categories of authors. Another group that appears to play an important role in the configuration of co-authorship relationships is that of the transients, whose members cooperate with $16.8 \%$ of one-timers and $26.9 \%$ of newcomers. These relationships are shown in Figure 2. 
Figure 2: Relationship between Research Categories and Centrality of Categories

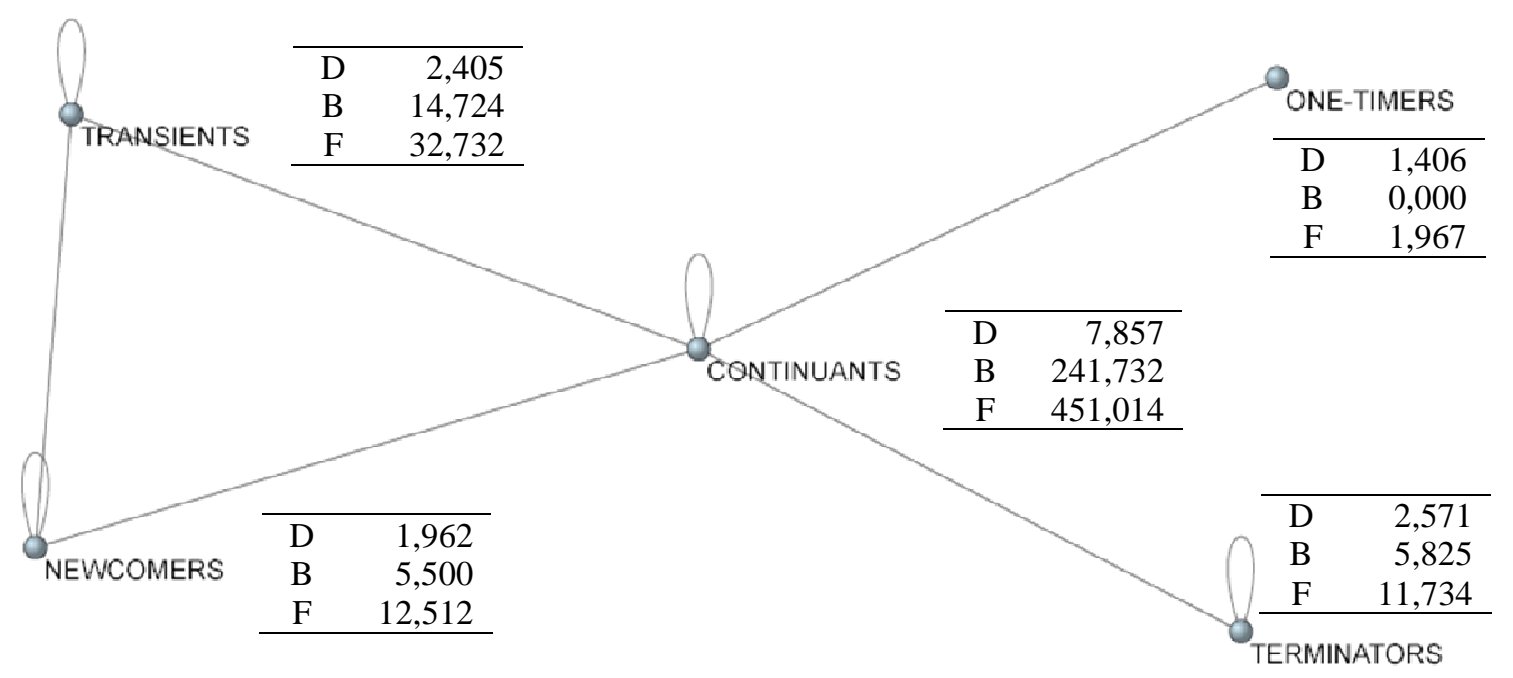

Note: $\mathrm{D}=$ degree centrality; $\mathrm{B}=$ betweenness centrality; $\mathrm{F}=$ flow centrality. The ties correspond to the image matrix resulting from the evaluation of the strength of the ties between categories and the density calculated for the overall connections between authors in the field. Only relationships whose density was greater than the density of the co-authorship matrix were considered.

Source: research results.

It is worth highlighting that these data show the intermediation role played by continuants in the connection of different categories of authors. The centrality measurements make this clearer still. This means that researchers in this category tend to be positioned on the path of cooperation relationships between authors, which enables us to believe in their influence on the flow and content of information (see betweenness centrality in Figure 2). Such aspects make sense when we admit, in accordance with Borgatti (2005), that, in the scientific field, social relationships are also channels of intellectual influence; relationships between actors are flows of influence that, through interaction, can affect the way other actors think or act (see centrality of flow in Figure 2). In the case of the network of collaboration between researchers, we can state that it is through social relations that the flow of ideas articulated as shared cognitive structures occurs.

In short, the data analysis shows the role played by continuants in the intermediation of relationships. Besides acting as channels/distributors of relations between authors of different categories, they are also responsible for the consolidation of production. The same observation is valid for transient researchers, especially because they are also a group that receives newcomers. In both cases, the results show the existence of a social mechanism linked to intermediation participating in the construction of scientific knowledge.

\section{Social Organization: Structured Growth}

The 256 authors identified in the 297 articles analyzed constitute the academic research community in organizational studies in the light of the institutional perspective and are identified through the nodes depicted in Figure 3 (see the year 2007). The graphic representation of the relationship between authors was generated from the sum of cooperation links for each year, so that each node represents a single actor and the ties indicate the existence of a relation of co-authorship at some time during the period under study. 
The high fragmentation of the network in itself can be considered a characteristic of this field because there are several small components - subgraphs whose nodes are connected to one another in accordance with the view of Wasserman and Faust (1994) - in addition to the large number of isolated authors not represented in Figure 3. These surround five other larger components and together represent $48.1 \%$ of the network, regarding the number of authors. The largest of them, the main component, involves $20.3 \%$ of all the authors who took part in scientific production during the period under study. The second largest component, in its turn, has the smallest proportion, with $14.5 \%$ of the total number of researchers in the field.

The configuration of the components enables us to perceive the inequality present in the formation of relationships. The same goes for the cluster coefficient, a measurement that checks the local network structure in terms of density (coefficient equal to 0.722). It is interesting to note that the fragmented character of the network is accompanied by greater local agglomeration of the nodes, which could potentially be a conditioning factor of research practices and sharing of perspectives. In light of this, the presence of a network with few connections and with many small components suggest restricted communications between different parts of the network, which could be a tendency to form groups of researchers sharing different interests and preferences among themselves, whether epistemological, theoretical or thematic. The longitudinal analysis of the social collaboration network (see Figure 3 ) allows us to observe this process over the years.

The growth in the number of authors and components, when observed in global terms, resulted in a low density configuration, with sparsely distributed relationships; with the passing of time, the average number of co-authorship ties per researcher decreased, although the overall volume of collaboration in the production of articles increased. However, this effect, when analyzed more closely, shows the existence of denser local connections among researchers, showing the organized growth of relationships over the time period under study. It can be seen that, as time goes by, the addition of co-authorship ties is guided by the formation and consolidation of components, especially the two largest. It is worth pointing out that most continuant researchers are present in these components, which guarantee the continuity of production, as seen previously, maintaining a high degree of productivity and attracting new relationships.

These circumstances strengthen the arguments that there may exist relevant social mechanisms that condition the existence of relationships between researchers, such as sharing common theoretical frameworks among authors. Furthermore, it is worth noting that the consistence of the low percentage of isolated authors over time (around 12\% in the period under study) is further evidence of consolidation of collaboration as a current practice in scientific production. This evidence strengthens the understanding that there is a structuration dynamic of scientific knowledge from the definition of theoretical frameworks that are shared, produced and influenced by the structure of knowledge in the field, groups and relationships among researchers. 
Figure 3: Transformation of the Network of Collaboration between Researchers

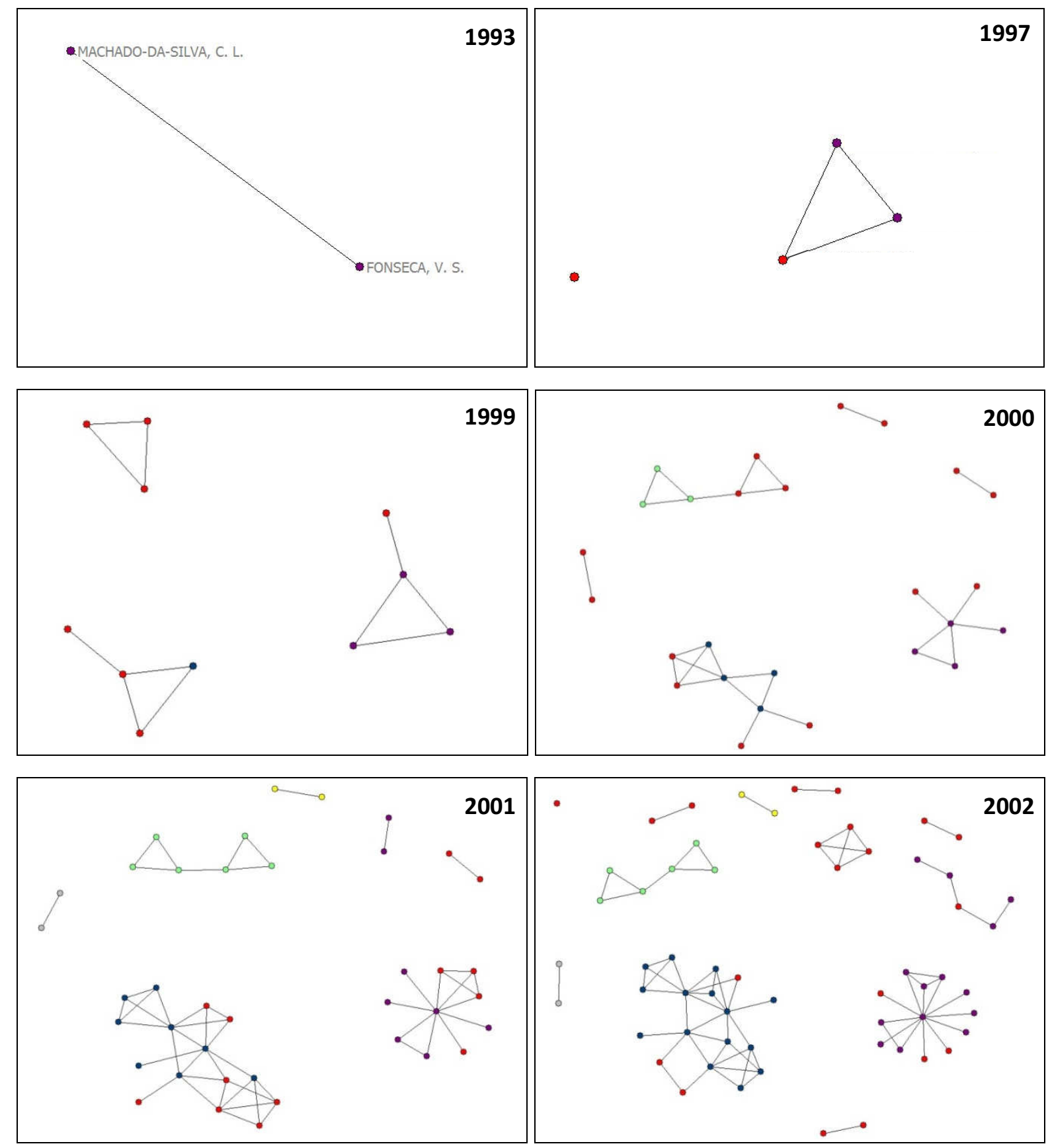


Figure 3 (continued): Transformation of the Network of Collaboration between Researchers
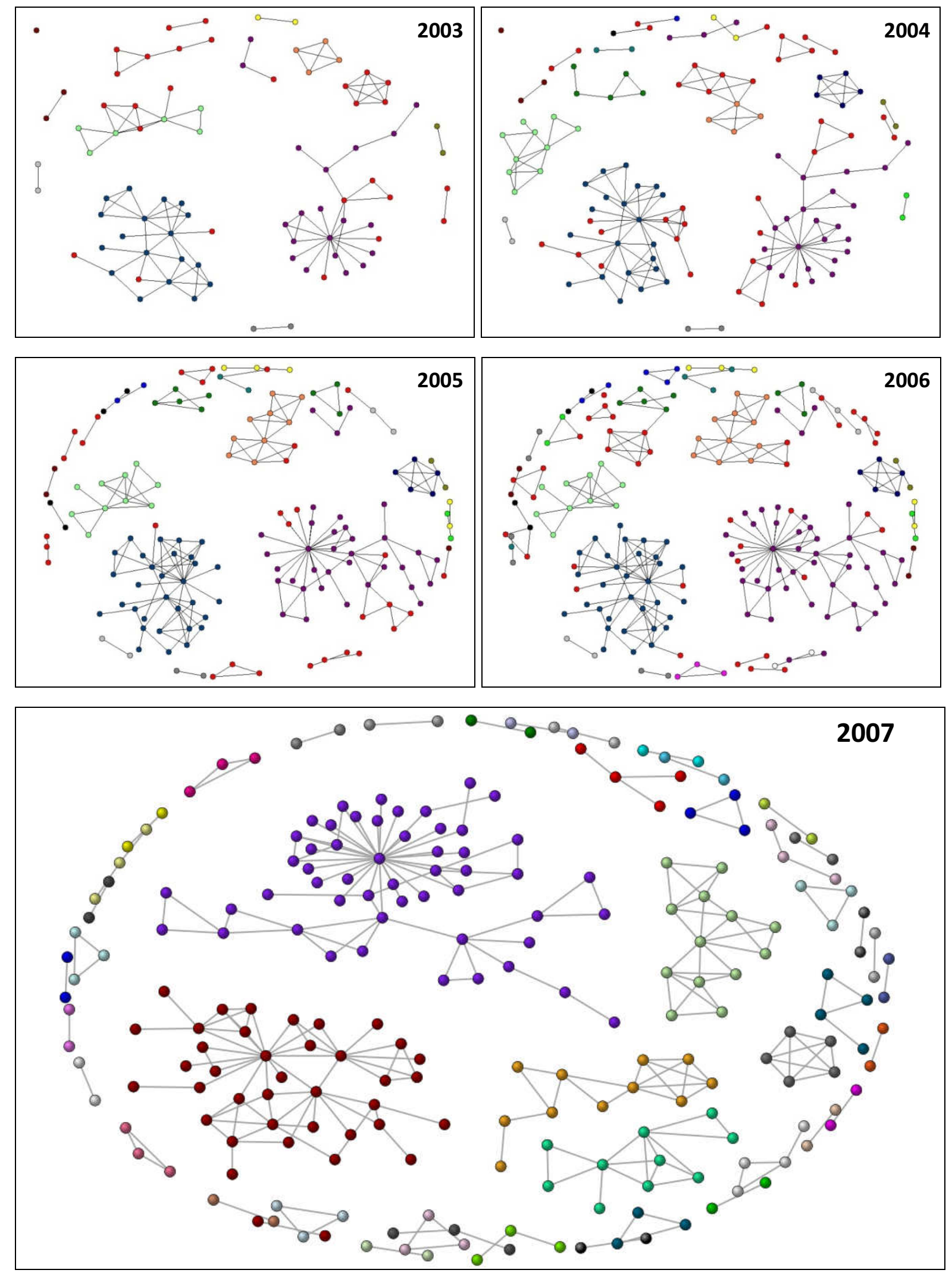

Note: The nodes in red are authors whose first publication occurred in the respective year of representation (up to 2006). Isolated nodes in the aggregate co-authorship network considering all the periods are not represented. Colors distinguish the components.

Source: research results. 


\section{Social Organization: Secondary Dynamic}

An important aspect which cannot be ignored, but one that is difficult to visualize when the analysis is concentrated around larger components, is the fact that over the years there has been greater expression on the margins of the network, where isolated authors and smaller components are located. Although we know that a considerable part of these are characterized as one-timers, the number of authors in this space practically doubled from 2002 to 2007. Between 2002 and 2004, there were 48 authors with production in the peripheral components. But more recently, from 2005 to 2007, this number rose to 95 researchers.

The same can be seen concerning the volume of articles produced, with a growth of almost $100 \%$ between the two periods, rising from 33 papers to 63. Data like these are very significant because they show the concentration of almost $70 \%$ of peripheral authors during this latest period (2005-2007), who produced $60 \%$ of the articles by this category of researchers.

Furthermore, these data show that the institutional approach in organizational studies has a secondary dynamic, although not organized more systematically, but which indicates diffusion of the perspective to beyond the frontiers of the larger components. There are also the growing cooperation indicators from each period, so that it would not be an exaggeration to imagine that the formation of new components or the broadening of those that already exist (whether peripheral or even the larger components) could become a reality in a short space of time due to the multiplication of channels through which the approach has been developed.

\section{Citations: Legitimate Cognitive Resources}

According to Giddens (1999), articles are not conceptions reduced to what is written but rather social practices inserted in the world and in the way this conjunction is organized by the agent himself. As such, they are absorbed and, therefore, continually interpreted and modified throughout the idea transmission process. Thus, they carry not only widely shared knowledge but also values and ideas depending on how they are organized and communicated (Scott, 2003). From this view, the possibility of studying articles in the aggregate, through the salience of how certain sets of cited authors or references are presented throughout the structuring of the field, makes it possible to understand the formation of domains of knowledge. Furthermore, the prominence shown by certain references raises analytical questions that not only have to do with theoretical or epistemological stances, but also the legitimacy and prestige of certain texts or authors as fundamental to the construction of later knowledge. From these points arose the interest in identifying and classifying cited authors according to their prominence in the articles selected for study.

The data collected showed a distribution of citations similar to international bibliometric patterns, with stratification characteristics, since of the 3,998 authors cited, around $57 \%$ were cited only once, while only $4.8 \%$ were cited over ten times. The existence of authors, who were cited far more often than the majority, shows their prominence in the field, be it because they are considered legitimate cognitive resources and adequate for scientific production, be it because they are seen as conceptual symbols (Small, 1978).

In this sense, it is worth recapping the idea that the practice of citing is reflexive and at the same time necessary for scientific communication and conditioned by the social context. In another sense, it provides conditions for the dynamic of reproduction involved in the (re)construction of scientific knowledge, considering it is recognized as a scientific value (Leydesdorff, 1998; Merton, 1957). Thus, the distribution of citations among authors, considered as a whole, also makes it possible to reflect on the bases of knowledge. Authors with greater academic recognition tend to be more influential and, therefore, have a greater impact on knowledge generated in the practice of scientific production, in that they are also considered favorable resources for sustaining and validating the ideas stated in scientific articles (Small, 1978). 
Having said this, it is interesting to note that among the six most cited authors, two are Brazilian: Scott, W.R. with 442 indications in the references; Machado-da-Silva, C. L. is next, with 417 citations, DiMaggio, P.J. with 361, Powell, W.W. with 337, Meyer, J.W. with 278 and Fonseca, V.S., cited on 274 occasions. The presence of two Brazilians, Machado-da-Silva and Fonseca, among the foreign authors considered classics in the field of organizational institutionalism reveals the growing weight that Brazilian researchers have gained in the intellectual structure of the institutional perspective in the country. Three other Brazilians also figure among the most cited authors, with between 150 and 100 indications in the cited references: Vieira, M.M.F. with 144, Carvalho, C.A.P. with 122 and Fernandes, B.H.R. with 115. These authors also figured among the cited authors with the highest hindex (Hirsch, 2005), a bibliometric index that indicates their representativeness as a valid theoretical framework for articles, which indirectly expresses their intellectual recognition by researchers in the field under study.

\section{CONCLUSIONS}

This study began on the assumption that the construction of scientific knowledge involves recursiveness between two dimensions, the social and the intellectual, which are at the same time a medium and outcome of the social activity of researchers. Their choices result in scientific production, be it in the way they establish collaboration relationships with their peers, be it based on references used to conduct their work. We sought, throughout the stages of research, to discuss these aspects, the main findings of which are briefly summarized here:

- Quantitative expansion in terms of researchers and articles: around 20\% a year, with higher levels of activity in recent years;

- Elaboration of the social organization around the institutional perspective, with greater cooperation between researchers and the formation of co-authorship clusters, with the two largest being responsible for $34.7 \%$ of researchers and $57.6 \%$ of production for the period;

- Organized growth involving some authors classified as continuant and transient, demonstrative of the stratification of production and relationships, since these groups are responsible for the intermediation of relationships and consolidation of production;

- Secondary dynamic based on the work of researchers located on the margins of the network, whose sporadic work can help legitimize the knowledge and reference frameworks;

- The fact that Brazilian researchers are among the most cited authors, a sign of their recognition and the formation of a legitimized local intellectual base in the production of knowledge in the field.

These results call attention to the influence of social relationships on the process of constructing scientific knowledge, which is the same as saying that it occurs through social networks of researchers. We found that the field of the institutional perspective in organizational studies in Brazil, in terms of collaboration for scientific production, configures a network fragmented around two main clusters, wherein are concentrated most of the articles and researchers.

However, in both components, the most central authors are also categorized as continuants, and are also those who have been active longest in the field. Although there are variations concerning the structural characteristics of these components, it was clear that the growth of the field occurred around them. Several reasons could account for this.

The first is the fact that the existence of more central and continuant authors means that they should be considered a force of diffusion and legitimization of knowledge practiced in the field in light of the social capital that they have mobilized (Zucker \& Darby, 1996). As such, they can concern themselves with cultivating relationships that can provide continuance to the intellectual development in which 
they are involved. Less intentionally, more central authors are involved in a large number of relationships and develop a set of contacts through which they gain visibility as an influential information channel (Wasserman \& Faust, 1994).

Therefore, it can be inferred that researchers with these characteristics are capable of a certain leadership in the sense of promoting the spread of ideas, mobilizing structures and generating scientific production. It should also be considered that hierarchical relationships between student and guidance advisor also have an influence on social configuration and scientific production. Figure 4 illustrates this aspect through continuant researchers, associating the origin of the two largest components of co-authorship with advising relationships at the doctorate and master's degree levels. It is interesting to note that, despite stemming from a common origin, both components developed separately, which may indicate different preferences concerning how to approach the organizational phenomenon in the light of institutionalism, despite the original guidance relationship.

Figure 4: Relationship between Continuant Researchers

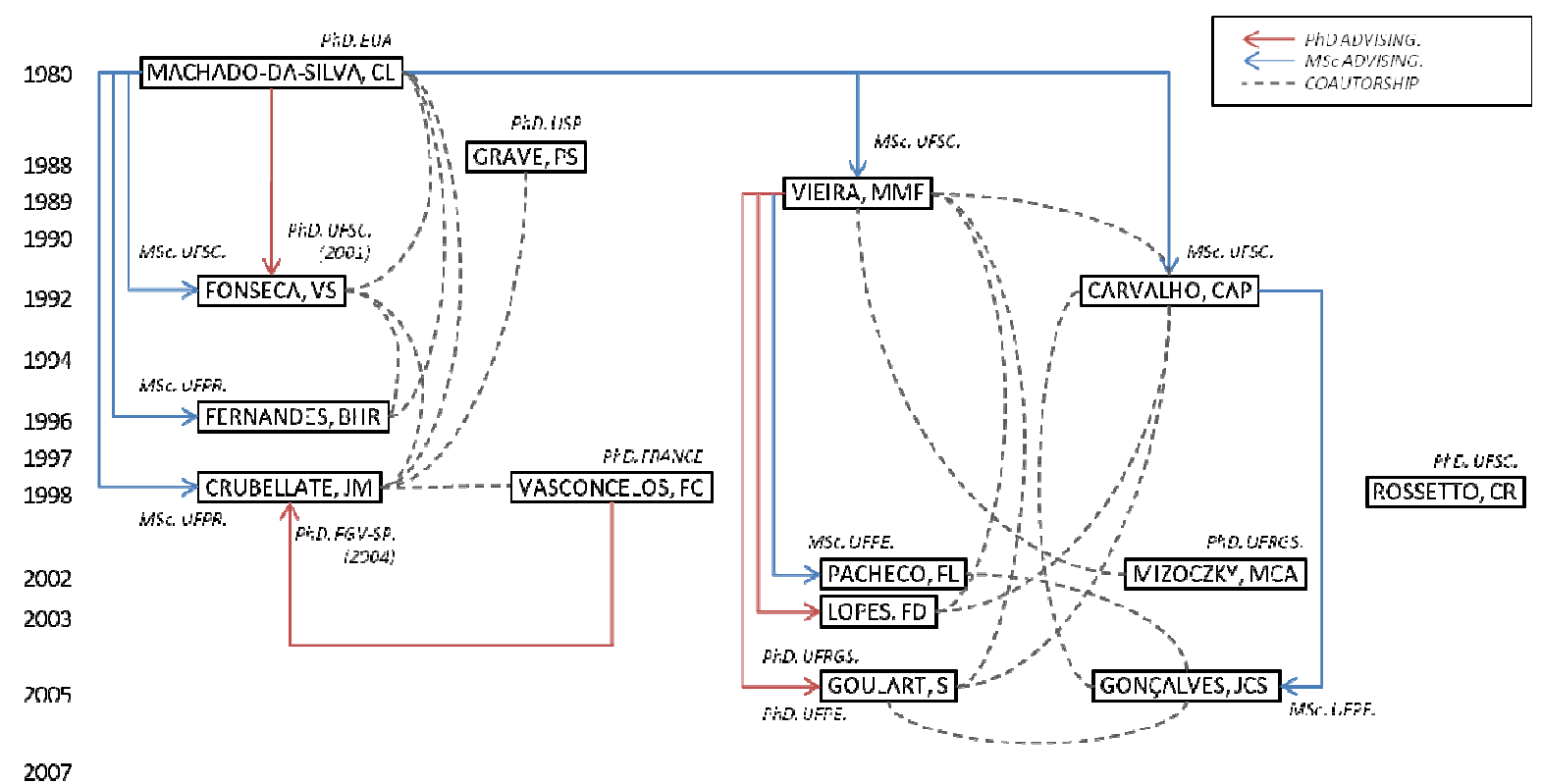

Note: the co-authorship ties are for 1993-2007.

Source: research results, based on data available from the Lattes Platform.

According to Braun et al. (2001), continuants play an important role in the construction of knowledge, especially the consolidation of production and the articulation of other categories of authors such as newcomers or transients. Furthermore, continuants act as disseminators, maintaining a high degree of connectivity with other actors. Researchers with a great reputation or those who represent access to resources, such as experience or knowledge, tend to be accessed more and, as a result of this, increase their prestige and at the same time influence the knowledge produced in the field (see Merton, 1996; Moody, 2004). Moreover, it is worth mentioning that these same researchers also have the greatest centralities of intermediation, a characteristic that is structurally connected to their potential control of interactions. In the situation under study, this means, on the one hand, dependence of some of the other authors and, on the other, their influence on the circulation of ideas in the field.

Relationship mechanisms of intermediation and stratification can stimulate the use of certain ideas, favoring their acceptance and encouraging new research. These mechanisms can also be responsible for diffusion beyond the frontiers of the components, since the reputation achieved by certain researchers, in addition to the fact that they are also the most cited, make them gatekeepers for the 
development of new works. Additionally, they can bring legitimacy to these studies, establishing a contact with knowledge that is already recognized and considered valid (McKinley, Mone, \& Moon, 1999).

Concerning what has been discussed here so far through mechanisms of intermediation and stratification, but still dependent on them, the cognitive structure can follow ceremonial paths. This means that certain cited units come to be viewed more as symbolic means of legitimizing ideas than an epistemological basis. It is worth pointing out that these aspects seem to be related to the gradual formation of a legitimate base through which the analysis of different phenomena is supported under the institutional perspective. Development of this matter would be expressed in the theoretical frameworks used by researchers and research groups, sketching not only the thematic diversity but also epistemological cuts and intellectual divergences found in the scientific debate.

Transposing these ideas to the field of scientific production, concerning this study, it could be said that published texts influence the structure of knowledge, not only as a repository of information but also because they render favorable elements that affect the dynamic of knowledge or the examination of academic knowledge through content analysis, authorship relations, transmission and genealogy of texts and ideas, and so forth. Another aspect that is of interest has to do with how patterns of authority and of social organization can influence scientific production. In this sense, it is viable to say that the authority of knowledge may be related to social authority patterns (groups, people, institutions), which would influence the arrangement of approaches, methods or foundational bases in the field. Furthermore, relationship structures between actors in the academic field can influence the way in which knowledge is organized, as observed by Fuller (2002).

Finally, we stress that although we have placed more emphasis on our analysis of the social dimension than the intellectual, we believe that both are recursively constructed and, therefore, need to be understood together. However, it should be stated that the continuation of this debate is necessary in terms of themes, knowledge structures and consolidation of academic programs, and will be the aim of a future work that is already in preparation by the authors of this paper.

\section{NOTES}

\footnotetext{
${ }^{1}$ Two texts prior to the year 1993 were found in the sources that were consulted: Venosa, R. (1982). A institucionalização de tipologias organizacionais: um estudo de caso. Revista de Administração de Empresas, 22(2), 23-36. and Machado, M. H. (1991). A sociedade e as organizações. Revista de Administração Pública, 25(3), 74-84. However, both deal with the institutional approach without expressing it as a specific analytical perspective for understanding the processes of institutionalization in the context of organizations. According to Caldas and Fachin (2007), organizational institutionalism was effectively launched in Brazil as an analytical perspective in a study conducted by Machado-da-Silva, C. L. (1991). Modelos burocrático e político e estrutura organizacional de universidades. In Núcleo de Pesquisas e Estudos em Administração Universitária (Org.). Temas de administração universitária (pp. 78-90). Florianópolis: OEA/UFSC, which was not included in the analyses of this study as it was not among the selected sources for this article.

2 The research sources included: Revista de Administração de Empresas [RAE], Revista de Administração de Empresas Eletrônica [RAE-E], Revista de Administração da Universidade de São Paulo [RAUSP], Revista de Administração Contemporânea [RAC], Revista de Administração Contemporânea Eletrônica [RAC-E], Revista de Administração Pública [RAP], Organizações \& Sociedade [O\&S], Revista Eletrônica de Administração [REAd], Revista BASE, Cadernos EBAPE.br, Revista de Administração Mackenzie [RAM], Brazilian Administration Review [BAR], Anais dos Encontros Anuais da Associação Nacional de Pós-Graduação e Pesquisa em Administração [EnANPAD], Anais dos Encontros de Estudos Organizacionais [EnEO] and Anais dos Encontros de Estudos em Estratégia [3Es]. The journals evaluated for 2007 were limited to the publications available up to the final data collection. The last editions consulted were: RAE-E, 6(2); RAE, 47(4); RAP, 41(5); Cadernos EBAPE, 5(4); RAC, 11(4); RAC-E, 1(3); BAR, 4(3); RAUSP, 42(4); READ, 13(3); RAM, 8(4); BASE, 4(3); O\&S, 14(2).
} 


\section{REFERENCES}

Astley, W. G. (1985). Administrative science as socially constructed truth. Administrative Science Quarterly, 30(4), 497-513.

Borgatti, S. P. (2005). Centrality and network flow. Social Networks, 27(1), 55-71.

Braun, T., Glänzel, W., \& Schubert, A. (2001). Publication and cooperation patterns of the authors of neuroscience journals. Scientometrics, 51(3), 499-510.

Caldas, M. P., \& Fachin, R. (2007). Paradigma funcionalista: desenvolvimento de teorias e institucionalismo nos anos 1980 e 1990. In M. P. Caldas \& C. O. Bertero (Eds.). Teoria das organizações (pp. 69-79). São Paulo: Atlas.

Dacin, M. T., Goodstein, J., \& Scott, W. R. (2002). Institutional theory and institutional change: introduction to the special research forum. Academy of Management Journal, 45(1), 45-57.

Davis, G. F. (2006). Mechanisms and the theory of organizations. Journal of Management Inquiry, 15(2), 114-118.

DiMaggio, P. (1995). Comments on "What theory is not". Administrative Science Quarterly, 40(3), 391-397.

DiMaggio, P., \& Powell, W. W. (1983). The iron cage revisited: institutional isomorphism and collective rationality in organizational fields. American Sociological Review, 48(2), 147-160.

Farashahi, M., Hafsi, T., \& Molz, R. (2005). Institutionalized norms of conducting research and social realities: a research synthesis of empirical works from 1983 to 2002. International Journal of Management Reviews, 7(1), 1-24.

Fuller, S. (2002). Social epistemology (2nd ed.). Bloomington: Indiana University Press.

Giddens, A. (1999). Estruturalismo, pós-estruturalismo e a produção da cultura. In A. Giddens \& J. Turner (Eds.). Teoria social hoje (pp. 281-320). São Paulo: UNESP.

Gordon, A. (2007). Transient and continuant authors in a research field: the case of terrorism. Scientometrics, 72(2), 213-224.

Greenwood, R., Oliver, C., Sahlin, K., \& Suddaby, R. (2008). Introduction. In R. Greenwood, C. Oliver, K. Sahlin, \& R. Suddaby (Eds.). The sage handbook of organizational institutionalism (pp. 1-46). Los Angeles: Sage.

Guarido, E. R., Filho (2008). A construção da teoria institucional nos estudos organizacionais no Brasil: o período 1993-2007. Tese de doutorado, Universidade Federal do Paraná, Curitiba, PR, Brasil.

Haveman, H. A., \& David, R. J. (2008). Ecologists and institutionalist: friends or foes? In R. Greenwood, C. Oliver, K. Sahlin, \& R. Suddaby (Eds.). The sage handbook of organizational institutionalism (pp. 573-595). Los Angeles: Sage.

Hirsch, J. E. (2005, November). An index to quantify an individual's scientific research output. Proceedings of the National Academy of Sciences of the USA, 102(46), 16569-16572.

Leydesdorff, L. (1998). Theories of citation? Scientometrics, 43(1), 5-25.

Liu, X., Bollen, J., Nelson, M. L., \& Van de Sompel, H. (2005). Co-authorship networks in the digital library research community. Information Processing Management, 41(6), 1462-1480. 
Machado-da-Silva, C. L., \& Fonseca, V. S. (1993). Estruturação da estrutura organizacional: o caso de uma empresa familiar. Organizações \& Sociedade, 1(1), 42-71.

Machado-da-Silva, C. L., Fonseca, V. S., \& Crubellate, J. M. (2005). Estrutura, agência e interpretação: elementos para uma abordagem recursiva do processo de institucionalização. Revista de Administração Contemporânea, 9(1ª Edição Especial), 9-39.

Mckinley, W., Mone, M., \& Moon, G. (1999). Determinants and development of schools in organization theory. Academy of Management Review, 24(4), 634-648.

Merton, R. K. (1957). Priorities in scientific discovery: a chapter in the sociology of science. American Sociological Review, 22(6), 635-659.

Merton, R. K. (1996). On social structure and science. Chicago: Chicago University Press.

Meyer, J. W., \& Rowan, B. (1977). Institutionalized organizations: formal structure as myth and ceremony. American Journal of Sociology, 83(2), 340-363.

Mizruchi, M., \& Fein, L. C. (1999). The social construction of organizational knowledge: a study of uses of coercive, mimetic, and normative isomorphism. Administrative Science Quarterly, 44(4), 653-683.

Moody, J. (2004). The structure of a social science collaboration network: disciplinary cohesion from 1963 to 1999. American Sociological Review, 69(2), 213-238.

Powell, W. W. (1991). Expanding the scope of institutional analysis. In W.W. Powell \& P. DiMaggio (Eds.). The new institutionalism in organizational analysis (pp. 183-203). Chicago: University of Chicago Press.

Rossoni, L. (2006). A dinâmica de relações no campo da pesquisa em organizações e estratégia no Brasil: uma análise institucional. Dissertação de mestrado, Universidade Federal do Paraná, Curitiba, PR, Brasil.

Scott, W. R. (1995). Symbols and organizations: from Barnard to the institutionalists. In O. Williamson (Ed.). Organization theory: from Chester Barnard to the present and beyond (pp. 38-55). New York: Oxford University Press.

Scott, W. R. (2001). Institutions and organizations (2nd ed.). Thousand Oaks: Sage.

Scott, W. R. (2003). Institutional carriers: reviewing modes of transporting ideas over time and space and considering their consequences. Industrial and Corporate Change, 12(4), 879-894.

Scott, W. R., \& Meyer, J. W. (1991). The organization of societal sectors: propositions and early evidence. In W.W. Powell \& P. DiMaggio (Eds.). The new institutionalism in organizational analysis (pp. 108-140). Chicago: University of Chicago Press.

Small, H. (1978). Cited documents as concept symbols. Social Studies of Science, 8(3), 327-340.

Wasserman, S., \& Faust, K. (1994). Social network analysis: methods and applications. Cambridge: Cambridge University Press.

Weick, K. E. (1995). What theory is not, theorizing is. Administrative Science Quarterly, 40(3), 385-397.

Zucker, L. G., \& Darby, M. R. (1996, November). Star scientists and institutional transformation: patterns of invention and innovation in the formation of the biotechnology industry. Proceedings of the National Academy of Sciences of the USA, 93(23), 12709-12716. 